\title{
Recent Progress in Design of Biomass-Derived Hard Carbons for Sodium Ion Batteries
}

\author{
Joanna Górka ${ }^{1}$, Cathie Vix-Guterl ${ }^{1,2}$ and Camelia Matei Ghimbeu ${ }^{1,2, *}$ \\ 1 Institut de Science des Matériaux de Mulhouse, Université de Strasbourg, Université de Haute-Alsace, \\ CNRS UMR 7361-15 rue Jean Starcky, 68057 Mulhouse, France; joanna.gorka@uha.fr (J.G.); \\ cathie.vix@uha.fr (C.V.-G.) \\ 2 Reseau sur le Stockage Electrochimique de l'Energie (RS2E), FR CNRS 3459, 33 Rue Saint Leu, \\ 80039 Amiens Cedex, France \\ * Correspondence: camelia.ghimbeu@uha.fr; Tel.: +33-38-960-8743 \\ Academic Editor: I. Francis Cheng \\ Received: 28 September 2016; Accepted: 30 November 2016; Published: 5 December 2016
}

\begin{abstract}
Sodium ion batteries (SIBs) have attracted lots of attention over last few years due to the abundance and wide availability of sodium resources, making SIBs the most cost-effective alternative to the currently used lithium ion batteries (LIBs). Many efforts are underway to find effective anodes for SIBs since the commercial anode for LIBs, graphite, has shown very limited capacity for SIBs. Among many different types of carbons, hard carbons-especially these derived from biomass-hold a great deal of promise for SIB technology thanks to their constantly improving performance and low cost. The main scope of this mini-review is to present current progress in preparation of negative electrodes from biomass including aspects related to precursor types used and their impact on the final carbon characteristics (structure, texture and composition). Another aspect discussed is how certain macro- and microstructure characteristics of the materials translate to their performance as anode for Na-ion batteries. In the last part, current understanding of factors governing sodium insertion into hard carbons is summarized, specifically those that could help solve existing performance bottlenecks such as irreversible capacity, initial low Coulombic efficiency and poor rate performance.
\end{abstract}

Keywords: hard-carbon; biomass; Na-ion batteries; energy storage

\section{Introduction}

Climate change and decreasing availability of cost-effective fossil fuels are of global concern regarding energy storage, leading toward a collective effort in finding alternative energy storage technologies. Among the existing and most efficient energy storage devices, such as supercapacitors, fuel cells and batteries, the latter are known to be high energy and power-density storage systems, making them ideal for portable electronics, hybrid electric vehicles and large-scale industrial equipment. All these industrial sectors use lithium ion batteries (LIBs) as they are the most common type of rechargeable battery currently available on the market. Even though they are satisfactory in meeting today's energy demands and ensure a way to limit our dependency on fossil fuels, the fast-growing population will soon call for even better, more efficient and cheaper energy conversion and storage solutions.

Lithium, the lightest metallic element, has many electrochemical advantages such as high voltage, high energy density, high specific power, as well as a wide range of operation temperatures and very good shelf life. In addition, the small radius of the lithium ion facilitates its diffusion in solids. On the other hand, all these advantages are counterbalanced by rapidly depleting lithium sources and its non-uniform distribution across the globe. Especially the development of electric vehicles and plug-in hybrid electric vehicles raises everybody's expectations as well as requirements for the materials 
employed. That is why there is urgency in finding alternative technologies, which would replace currently used LIBs. Sodium as the 6th most abundant element on Earth can be an excellent alternative to lithium [1,2], not only taking into account its abundance and uniform distribution in the Earth's crust, but also its chemistry. Sodium's redox potential versus standard hydrogen electrode is only $0.3 \mathrm{~V}$ higher than the one of lithium, which makes it very appealing for rechargeable batteries $[3,4]$. This concept has been already demonstrated in sodium-air cells [5], sodium-sulfur cells [6], ZEBRA cells (Na-NiCl2) [7] and sodium ion batteries (SIBs) [8]. At this point, it is important to mention that all aforementioned types of cells have very different levels of maturity: ZEBRA and Na-S are commercial, $\mathrm{Na}$-ion is very advanced though very little commercialization has occurred, whereas Na-air cells still need extremely long-term research. Moreover, Na does not alloy with $\mathrm{Al}$ to enable the use of cheap $\mathrm{Al}$ current collectors; it also exhibits high voltage [9] and has the ability to operate at room temperature, rendering it a portable and inexpensive electrode- and electrolyte-compatible material.

The intercalation of $\mathrm{Na}$ into graphite is less favored compared to lithium, and many studies have assigned this behavior to the bigger size of $\mathrm{Na}$ compared to Li. This explanation cannot be sustained by experimental data since $\mathrm{K}, \mathrm{Rb}$ or $\mathrm{Cs}$ possessing even larger sizes than $\mathrm{Na}$ exhibit, contrarily, greater electrochemical capacity than Na. Recent DFT (density functional theory) theoretical studies suggest that the unfavorable intercalation of $\mathrm{Na}$ arise mainly due to the weaker binding to the graphite compared to $\mathrm{Li}$ and, in addition, to a certain competition with the metal ionization energy [10]. Besides these factors, the competition between the cations for aromatic rings and the solvent must be considered since the binding energy of metals is strongly modified in the presence of solvents [11,12]. Also sodium ions prefer octahedral and prismatic sites [13] compared to octahedral and tetrahedral sites for lithium [14]. These facts are the main reason for some difficulties associated with Na intercalation in SIBs and their worse performance in terms of specific energy and power density, when compared with LIBs. It has been shown that sodium-equivalent lithium-based compounds do not exhibit satisfactory performances and, therefore, to advance SIB technology, new electrode chemistries have to be found.

While for LIBs the most commonly used anode material is graphite, and lithium insertion takes place between graphene layers, sodium presents more difficulties with intercalation into graphite and makes graphite unsuitable for SIBs from a practical point of view $[15,16]$. In the work of Stevens et al. [17], for the first time, hard carbons were investigated as anode materials for electrochemical $\mathrm{Na}^{+}$insertion/extraction. The obtained results, although lower than for lithium insertion into graphite, displayed reversible capacities of $300 \mathrm{mAh} / \mathrm{g}$ and garnered attention for this type of carbonaceous material.

Hard carbons are usually prepared by pyrolysis of organic polymers or sugars at temperatures not exceeding $1500{ }^{\circ} \mathrm{C}$ [18]. The lack of ordering in the c-direction in otherwise almost perfect hexagonal network of planar carbon atoms makes them difficult to graphitize. In a structure like this, the amorphous areas are mixed with more graphitic-like domains in which strong cross-linking immobilizes and prevents the development of true graphitic structure even at high temperatures [19]. The susceptibility to graphitization depends on the nature of carbon precursor and is greatly enhanced for highly condensed aromatic hydrocarbon precursors. From a fundamental and comprehensive studies viewpoint, phenolic resin-derived carbons are very promising for electrochemical Na-storage due to precise control of the carbon physical and chemical properties [20-23]. There are a number of very interesting works recently published showing Na cells prepared with porous carbon/graphene composite, expanded graphite, 3D carbon frameworks or 2D carbon nanosheets [24-27]. However, the focus of this mini-review is placed on hard carbons derived from biomass as they have true potential not only to improve the performance of sodium-based energy storage technologies but also to help reduce the large quantities of biowaste produced every year. The potential of such a carbon precursor was explored earlier for LIBs, although most of that research is now devoted to SIBs [28-31]. In order to get the most complete picture of the topic, this paper discusses, in the first section, the issues concerning the choice of carbon precursors, taking into account their chemistry and yield. The focus of the following part links the microstructure and textural properties of carbons with their performance, 
while the last section attempts to explain the current understanding of $\mathrm{Na}$ insertion into hard carbons and especially all the performance bottlenecks, which for now limit SIB commercialization.

\section{Precursors and Yield}

Most of the materials already studied as possible precursors for hard carbons are either sugars, like sucrose [32-34] and glucose [35,36], peels of fruits produced and consumed in certain parts of the world in large quantities (apples [37], bananas [38,39], shaddock [40,41], and peanuts [42]) or the most abundant natural polymers such as cellulose [43-45] and lignin [46,47], derived from wood processing and other sources. Usually, the synthesis of hard carbon using biomass waste involves several steps such as washing with water, drying, eventual activation, followed by thermal treatment in an inert atmosphere at high temperatures between $600{ }^{\circ} \mathrm{C}$ and $1600{ }^{\circ} \mathrm{C}$ (see Figure 1 from ref. [37]).

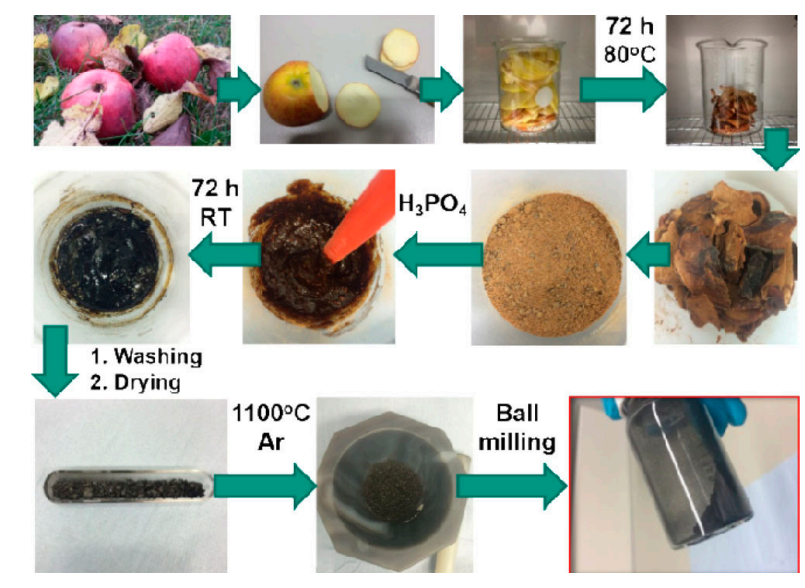

Figure 1. Synthesis scheme of apple-biomass-derived hard carbon. Reprinted with permission from [37]. (C) 2016 WILEY-VCH Verlag GmbH \& Co. KGaA, Weinheim.

There are a few reports presenting hard carbons obtained from not very obvious sources, such as silk protein [48] or harmful algal blooms [49]. From an economical point of view, it would be ideal to find well-performing material coming from a very abundant source, with a utility in SIBs that does not compete with the material's other applications (e.g., carbons from oatmeal proved to perform well in SIBs but oatmeal is first and foremost a valuable food); it should also be cheap and a real biowaste. Algal harmful blooms can serve as an example of such a material. Meng et al. [49] reported that certain types of algae, especially the blue-green, produce toxins, which can be life threatening to humans, as well as farm and wild animals. Cyanobacteria released by these algae are carcinogenic, and can be accumulated in aqueous organisms. In addition, the cost of neutralizing the negative impact of harmful algal bloom on local communities can be as high as $2-4$ billion dollars per year. That is why there is lots of interest in finding ways of converting harmful algae bloom into high-value functional materials with the "trash to treasure" approach.

Another aspect of choosing the precursor is that each one presents a unique chemical composition which translates into a different structure and/or morphology that eventually influences their performance when tested against sodium. Many of the biowaste-derived precursors exhibit quite heterogeneous structure consisting of a variety of biopolymers: hemicelluloses, lignins, free sugars, pectins, proteins and crystalline cellulose [50]. Lignin and hemicelluloses are known to be highly cross-linked and non-crystalline, which make them non-graphitizable in the temperature range usually used to prepare negative electrodes for SIBs. The pyrolysis of lignin usually results in converting biomass into porous carbons [51], especially if lignin contains some impurities as a residue coming from the production process. Thus, taking this into account, different biowaste materials will produce carbons with different structural characteristics. For example, banana peels contain $\sim 20 \%$ of pectin, another type of biopolymer with similar structure to lignin but bearing sugar units within [51]. 
During pyrolysis, gases such as $\mathrm{CO}_{x}, \mathrm{CH}_{4}, \mathrm{H}_{2}$ and $\mathrm{H}_{2} \mathrm{O}$ are released, while the rest of the structure undergoes extensive cross-linking and even aromatic ordering to some extent. If there are free sugars present in the precursor's structure, under pyrolysis conditions they may form a viscous liquid in which graphene sheets align themselves in a pitch-like fashion, before the structure is fully carbonized [52]. As mentioned before, the graphite structure should be avoided because of too little interlayer spacing to intercalate Na-ions. Precursors like banana peel thus seem to be the ideal material for SIB anodes with their well-balanced fractions of lignin and pectins, since one prevents crystallization of equilibrium graphite and the other enables partial ordering of the graphene layers. It has been reported that intercalation of $\mathrm{Na}$ into such pseudographitic structures is significantly improved. Shaddock peel is another abundant, renewable and environmentally friendly carbon precursor. It contains around $78 \%$ hemicelluloses, $7 \%-21 \%$ pectin and some sugars [53]. Thanks to a large quantity of highly cross-linked and non-crystalline hemicelluloses, the derived carbon is non-graphitic, thus appropriate for SIB studies [38]. The amount of hemicelluloses and lignins means the non-graphitizable component in peat moss [54] and shaddock peels are similar, although unlike the latter, peat moss also contains $20 \%$ of $\alpha$-cellulose which is expected to graphitize at low temperatures. It is anticipated that this part stays in place after carbonization and in so doing grants mechanical strength to the whole carbon framework.

For most natural precursors discussed above, the main criterion was to have a diverse and well-balanced chemical composition not only for the fully graphitizable structure, but also for possessing good mechanical resistance. It is also worth mentioning that there is a couple of precursors naturally doped with heteroatoms. It has been shown for both LIBs and SIBs that doping with heteroatoms is an effective strategy to enhance the performance of carbon electrodes. For most of the materials, synthesis methods such as chemical vapor deposition, thermal annealing with certain gases, plasma treatments or arc-discharge were used [55-58], although in many cases necessitating the involvement of toxic precursors, sophisticated equipment or rigorous conditions [55-58]. Thus far for sodium ion batteries, only two carbons prepared from naturally doped precursors have been studied: (i) carbons obtained by hydrothermal conditioning of N-rich oatmeal and its subsequent carbonization [59]; and (ii) carbons derived from pyrolysis of lotus petioles, naturally containing fluorine [60]. In general, heteroatom doping is likely to increase the repulsive interaction between carbon layers and by this enlarge the interlayer spacing, which is expected to improve material performance towards sodium (see Figure 2, taken from ref. [59]).

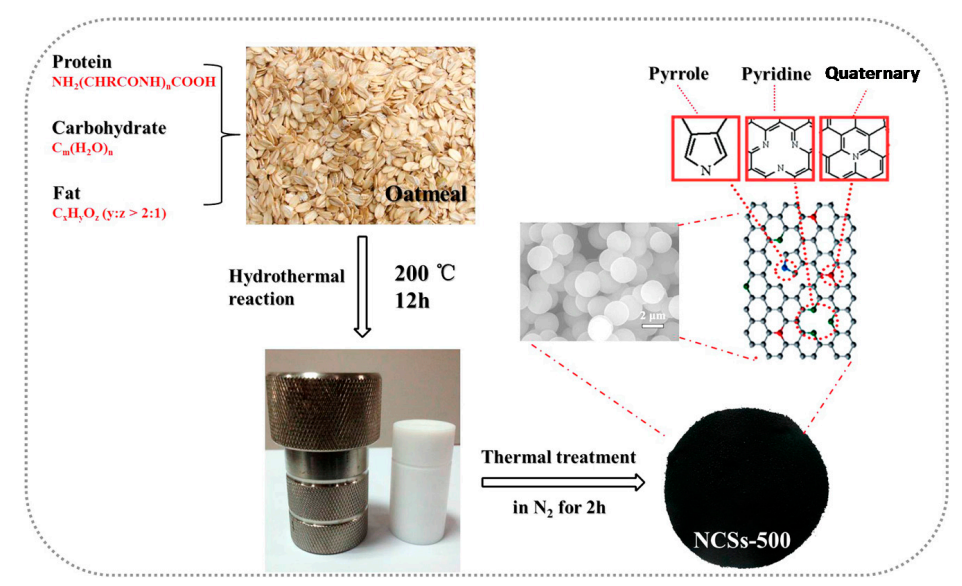

Figure 2. Schematic illustration of the synthesis of nitrogen-doped carbon microspheres (NCSs) derived from oatmeal. Reprinted with permission from [59]. Copyright (c) 2016 Elsevier Ltd.

Another interesting aspect, which is often neglected by the battery community, is the fact that biomass-derived carbon precursors possess lots of intrinsic impurities [61-63], such as $\mathrm{Na}, \mathrm{Si}, \mathrm{Zn}$, etc. (some examples are listed in Table 10 in ref. [61]) and their effect on the SIBs' performance is not evaluated. Only in some papers [54] acidic treatments are performed to remove such metallic impurities. 
Another thing that must be taken into consideration is carbon yield obtained after pyrolysis of biowaste-derived precursors. It is commonly assumed that biomass is a cheap source of carbon, but one has to remember that in most cases the precursors for amorphous carbons are not high in carbon content (see Table 9 in ref. [61]). In general, the precursors can be classified as: (i) bio-waste such as banana peels, which are very cheap but have low yield; (ii) cellulose and lignin-thanks to well-established extraction processes-which can be considered low cost renewable sources exhibiting high yield ( $50 \mathrm{wt} . \%)$; (iii) sugars such as sucrose and glucose that are actually cultivated for human needs and are therefore not suitable for industrial purposes. The comparison of pure raw materials like sucrose, lignin, starch and cellulose clearly shows carbon yield less than $10 \mathrm{wt} . \%$ for most of them, except lignin after carbonization at $1000{ }^{\circ} \mathrm{C}$ [48]. Lignin structure resembles to some extent the structure of phenolic resins and gives a similar carbon yield of approximately $50 \mathrm{wt} . \%$. Although this is a significant improvement, it also limits the spectrum of choices and raises the challenge of fabricating carbonaceous anode materials with high performance using mostly lignin.

\section{Microstructure and Texture}

As discussed before, the ideal carbon material should be composed of the amorphous parts mixed with graphitic domains. XRD (X-ray diffraction) is usually used to obtain information about the interlayer spacing between graphene sheets, which is determined based on the position of (002) diffraction peak at $26^{\circ}$ of $2 \theta$ found for equilibrium graphite. Its position shifted towards lower $2 \theta$ angles corresponds to bigger $\mathrm{d}_{002}$ spacing and thus indicates the presence of distorted graphitic planes in the material $[47,64]$. Also from the width ratio of the $(100) /(110)$ and $(002)$ diffraction peaks one can calculate the number of stacked graphene sheets [65]. It is well known that the degree of graphitization can be improved by increasing the temperature of pyrolysis [66].

Figure 3a shows the evolution of $d$-spacing with the carbonization temperature for various biomass precursors. As a general trend, the d-spacing decreases from $\sim 4.2$ to $3.5 \AA$, with the increase of the temperature from 500 to $1600{ }^{\circ} \mathrm{C}$. We noticed as well that the precursor used has a significant impact on the d-spacing due to the different composition as explained before.

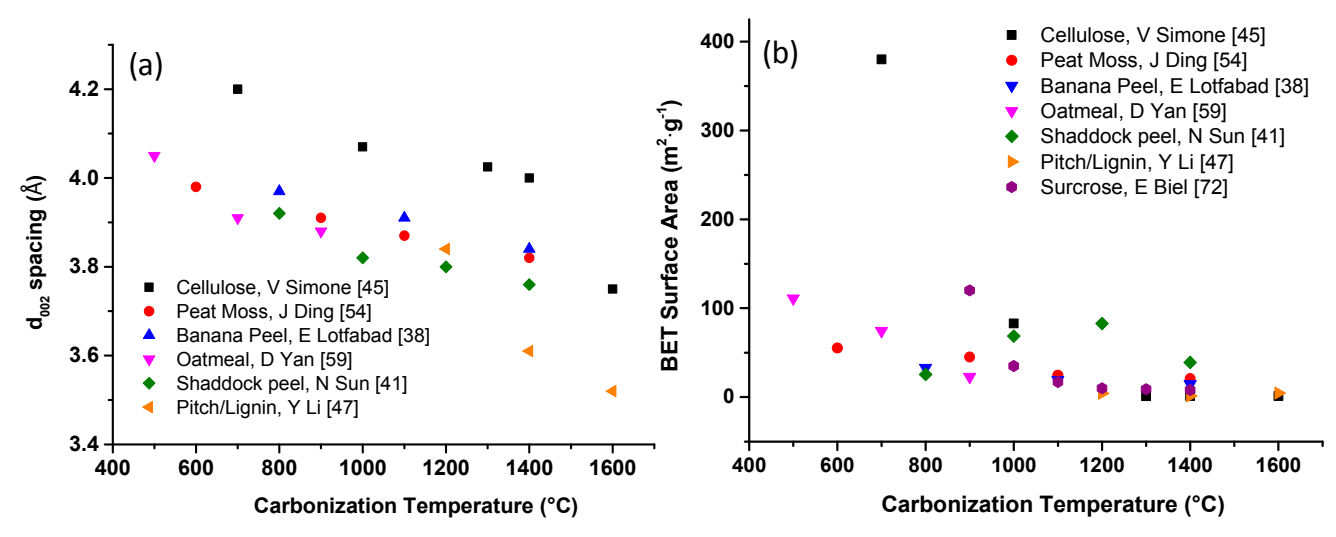

Figure 3. Correlation between (a) $\mathrm{d}_{002}$ spacing and (b) Brunauer, Emmett and Teller (BET) surface area and the carbonization temperature of different biomass-derived carbons.

The estimation of the degree of graphitization can be done also based on the Raman spectra, where carbon materials exhibit two characteristic bands at $\sim 1350 \mathrm{~cm}^{-1}$, the D-band corresponding to the defect-induced mode, and, at $1580 \mathrm{~cm}^{-1}$, the G-band corresponding to the graphitic mode. The ratio of $\mathrm{I}_{\mathrm{D}} / \mathrm{I}_{\mathrm{G}}$ usually indicates the degree of graphitization and decreases with the sample's ordering induced at high temperatures [66]. If graphitic domains are well developed they can also be seen with TEM. The schematic illustration of how the structure of hard carbons looks is presented in Figure 4 and corresponds with the "falling cards model" [67]. 

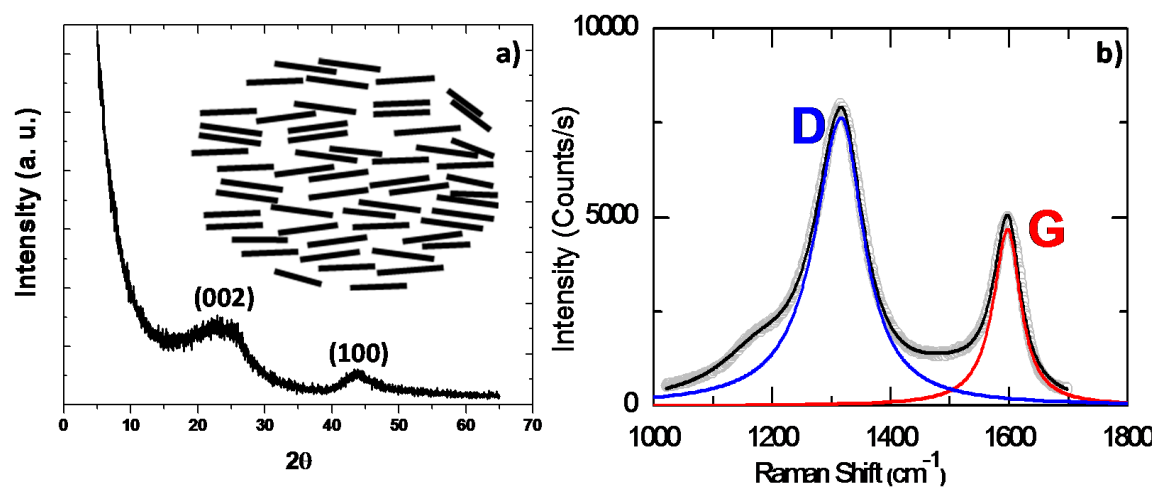

Figure 4. Typical X-ray diffraction (XRD) pattern (a) and Raman spectrum (b) for typical hard carbon. Reprinted with permission from [68] (c) The Author(s) 2015. Published by ECS.

Development of a porous structure during pyrolysis depends on the chemical composition of the precursor because varying amounts of different gasses can evolve and the pyrolysis conditions itself. Nitrogen adsorption measurements are usually utilized to obtain information about the porosity of the material, including Brunauer, Emmett and Teller (BET) surface area, micropore volume and pore size distribution. It is well known that microporosity of the sample increases with the degree of cross-linking found in the carbon precursor [69]. For example, in the case of carbons prepared from sugars, the BET surface can be as high as hundreds of $\mathrm{m}^{2} / \mathrm{g}$ when carbonization is carried out at not too high a temperature [70]. Temperatures above $1000{ }^{\circ} \mathrm{C}$ cause a drastic decrease in microporosity which continues to drop-albeit in a much steadier way above $1200^{\circ} \mathrm{C}$-reaching values smaller than $10 \mathrm{~m}^{2} / \mathrm{g}[34,45,65,66,71,72]$. Figure $3 \mathrm{~b}$ illustrates the correlation between the specific surface area and the carbonization temperature of different biomass carbon precursors. The temperature but also the precursor influence the specific surface area.

Specific surface area can be further tuned by pre-treatment of carbon precursor $[32,40,73]$ or post-carbonization treatments [34]. The latest reports suggest for SIBs that rather low surface area carbons are preferred and perform better. Also, recently it was reported that pyrolysis performed under high gas flow rate is an effective way of lowering microporosity and specific surface area values [68]. That kind of approach proved successful in flushing away the released gases, which otherwise would have enough time to react with the carbon surface causing extensive burnout and development of porosity [71]. Another advantage of high flow rates is the increase (almost twice) of the yield of final carbon [68], which as mentioned before is usually quite low for biowaste-derived carbons.

On the other hand, different types and quantities of chemical complexes (usually $O$-containing) are being formed during pyrolysis and this changes the chemistry of the carbon surface. These complexes are known to enhance carbon surface wettability but also the reactivity with an electrolyte, a feature very important for materials used in SIBs. Thus, the preparation of ideal carbon anode materials may need to make some compromises in the pyrolysis step and may require the addition of some post-synthesis treatments to deliver suitable physico-chemical properties to the carbon material to boost their performance in SIBs.

As much as in microstructure, biowaste-derived hard carbons also exhibit quite broad diversity in macroscopic structures. Most carbons obtained from sugar sources are characterized by spherical morphology with a usually smooth surface as shown in refs. [32-36]. Even carbons prepared by hydrothermal treatment of glucose in the presence of $\left(\mathrm{NH}_{4}\right)_{2} \mathrm{HPO}_{4}$ [32], which resulted in obtaining carbons doped with $\mathrm{P}$ and $\mathrm{N}$, still had similar morphology to undoped analogs. While the size of nanoparticles differs from report to report, the general trend indicates the range from $200-400 \mathrm{~nm}$ to 1-2 $\mu \mathrm{m}$. Much smaller carbon nanoparticles $(40-50 \mathrm{~nm})$ also with spherical morphology were obtained by flame deposition of coconut oil [74], although the change in carbon precursor as well as the use of piranha solution led to visibly rougher surface of the carbon nanoparticles. Hollow 
carbon nanospheres were synthesized by hydrothermal carbonization of glucose in the presence of a latex template [35]. The decomposition of glucose at a high temperature resulted in the formation of a thin layer of amorphous carbon around the latex. The latter, which was thermally unstable at high temperatures, was removed at $1000{ }^{\circ} \mathrm{C}$ producing hollow carbon spheres. Regarding different morphologies, carbon nanofibers derived from cellulose were reported by Luo et al. [43] Field Emission Scanning Electron Microscopy (FESEM) images revealed that cellulose samples were mostly composed of smooth nanofibers with a length of several microns and width of 50-100 nm. Another example of carbon nanofibers is shown by Jin et al. In this case, the authors selected lignin as a biowaste-derived precursor blended with polyacrylonitrile (PAN) [46]. It has been reported elsewhere that, due to heterogeneous and branched structures of technical lignin, lignin solutions are more susceptible to electrospray than fiber formation if no other polymers are added. PAN has the advantage of being one of the best precursors to produce strong and uniform carbon fibers [75,76]. Different blends of PAN and refined lignin (RL) were electrospun to yield long and smooth carbon nanofibers with average diameters increasing from $\sim 200 \mathrm{~nm}$ at $10 \%$ RL to $500 \mathrm{~nm}$ at $50 \%$, which are much finer than the carbon nanofibers produced from pure Alcell lignin solutions (without binder/additive polymer). Interesting transition from fiber to ribbon-like or layered morphology demonstrates the work focused on chemically crushed wood cellulose fibers [44]. The ribbon-like structure was obtained by treating natural wood fiber with TEMPO (2,2,6,6-tetramethylpiperidine-1-oxyl), which can selectively oxidize the $\mathrm{C} 6$ hydroxyl group in the glucose unit of cellulose chain to carboxyl group. Thanks to that, wood fibers were partially unzipped and formed a ribbon-like structure. Moreover, this allowed forming more compact carbon paper with less surface area exposed, thus showing better performance against Na compared to pristine carbon paper. The preparation scheme of such a binder-free and self-sustained carbon paper electrode is presented in Figure 5.
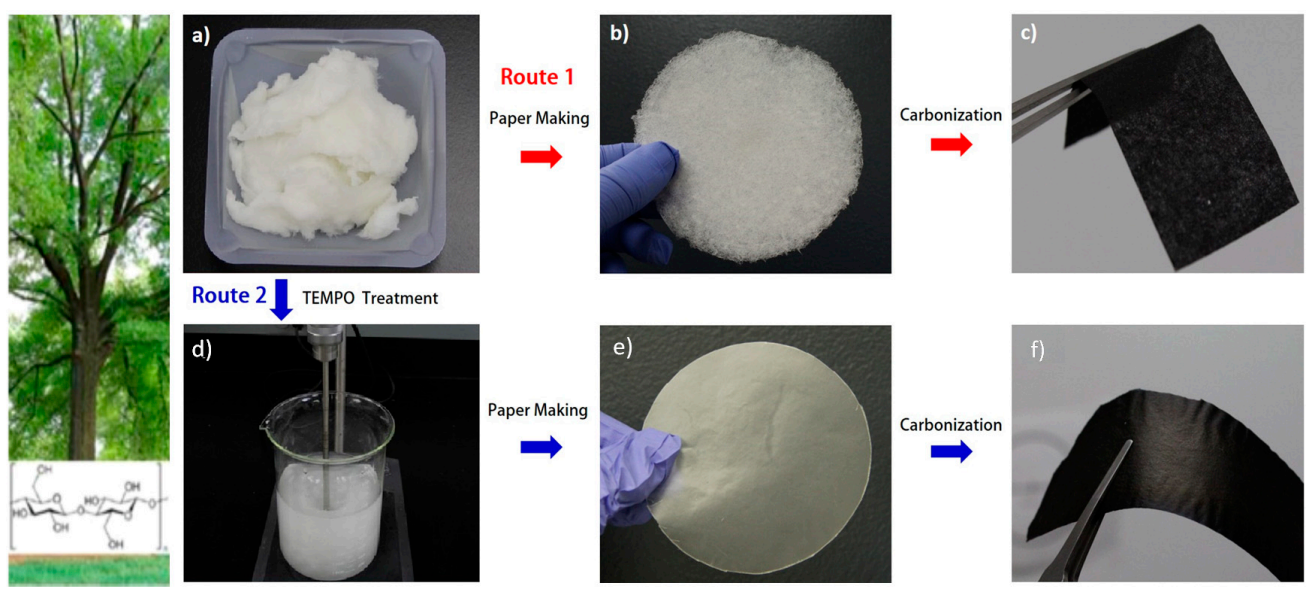

Figure 5. Steps of achieving two types of carbonized paper. In route 1, (a) natural wood fiber was directly used to make a (b) paper and (c) further carbonized to obtain pristine carbon paper. In route 2 , the wood fiber was first oxidized by (d) TEMPO treatment, and then made into (e) a paper and carbonized to obtain (f) oxidized carbon paper. Route 2 leads to a much denser paper and carbonized carbon, which are more suitable for SIB anode applications. Reprinted with permission from [44]. Copyright (C) 2015 American Chemical Society.

Many works $[38,39,42,54]$ aim at proving the legitimacy of the claim that the openness of sheet-like morphologies is more favorable for ion diffusion as they lead to better electrochemical performance in contrast to micron or submicron size particles. It is true that the best performing biowaste-derived hard carbons reported thus far are characterized by a layered or foam-like hierarchical structure, although it seems to be quite clear that this feature is not the only one entirely responsible for the electrochemical performance. For example, carbon materials obtained by pyrolysis of shaddock peel [41] show similar capacity to the anode prepared from peanut skin-derived hierarchical carbons [42]. While the structure 
of the first material can be described as honeycomb-like with large cavities and thin walls, the second material features just flat sheets. The interlayer spacing calculated from XRD patterns for both materials were found to be similar. However, both anodes differ in regards to specific surface area, the shaddock peel derivation being basically non-porous while the peanut skin-derived carbon is highly porous due to $\mathrm{KOH}$ activation. The reason for the similar performance can be associated with the fact that both features (macroscopic structure and degree of porosity) play a role and have to complement each other. Following this trend, sodium ion battery anodes from banana peels [38] and carbon nanosheet frameworks prepared from peat moss [54] were reported. Both take advantage of a cellular structure, unique to the precursor and mild air activation used to create sufficient porosity to reduce $\mathrm{Na}$ diffusion distances. The stem leaves of peat moss are mostly composed of clear cells called hyaline cells. Thanks to a large volume of hyaline cells and thin yet flexible cell walls, the peat moss possesses great water-adsorbing and water-holding properties [77]. When the water and cytoplasm are removed and only the cell walls remain, the whole structure looks like the interconnecting network of macroscopic voids. It was discovered that after pyrolysis the sheet-like walls in this open macroporous structure are only $60 \mathrm{~nm}$ thin. Consequently, this combined with a post-pyrolysis activation, promotes faster sodiation of the anode material. A similar concept was exercised in the case of banana peel-derived carbons [38], which resulted in obtaining carbon material considered to be a direct electrochemical analog to graphite in LIBs in terms of the overall charge storage capacity, great cycling stability, Coulombic efficiency, large and nearly flat voltage plateau below $0.1 \mathrm{~V}$, and minimal charge-discharge hysteresis. The final example of a biowaste-derived carbon membrane was presented by Li et al. [78]. The authors prepared the membrane by one-step thermal pyrolysis of natural leaf (Figure 6) and studied it directly as a binder-free, current collector-free anode for rechargeable SIBs.

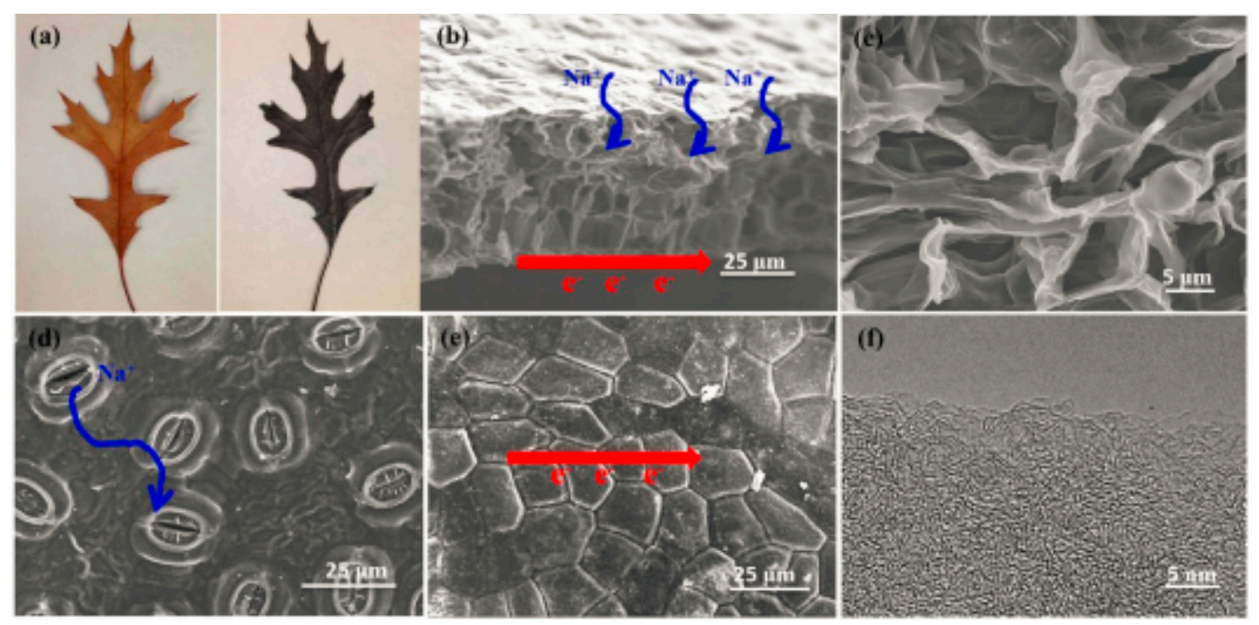

Figure 6. (a) Digital pictures of a dried leaf before and after carbonization; (b) Scanning Electron Microscopy (SEM) image of the cross-section of the carbonized leaf; (c) Magnified SEM image of the carbon nanosheet in the sponge layer; (d) SEM images of the stomata distributed uniformly on the back surface; (e) SEM image of the bricklike grains on the upper surface; (f) HRTEM image of the carbonized leaf. Reprinted with permission from [78]. Copyright (C) 2015 American Chemical Society.

Natural leaves, in addition to being a very abundant biomass source, possess proper chemical composition and are characterized by some features that help them to outperform carbons obtained from other biowaste sources. By having anisotropic surfaces with stomata on the back side of the leaf, in addition to the bulk of the leaf being composed of overlapping carbon nanosheets and having a nonporous upper surface, make them a complete, binder/current collector-free anode. The pores in carbonized leaf are in the macropore range, meaning low surface area and thus smaller probability for SEI (solid electrolyte interface) formation. Also the fact that the thickness of these free-standing membranes is between 50 and $200 \mu \mathrm{m}$ and the leaves remain flat after carbonization 
makes the fabrication of large-area, low-contact resistance membranes very easy by simply stacking leaves together before the pyrolysis. As highlighted, most of these biomass-derived carbons exhibit three-dimensional architectures with linked macropores. Such morphologies favor the electrolyte penetration into the carbon framework and shorten the diffusion pathways for $\mathrm{Na}^{+}$ions. Therefore, enhanced ion diffusion may lead to improved capacity.

\section{Performances}

In 1970, Herold and co-workers mentioned that sodium vapor can be stored by non-graphitic carbons through adsorption and insertion [79]. Later research accompanying commercialization of $\mathrm{Li}$ ion batteries established a more clear relationship between the amount of lithium uptake and the carbon microstructure showing that the lithium storage capacity is proportionally related to the number of single layer sheets and micropores. The mechanism for sodium insertion seems to be analogous to the one found for lithium $[17,80,81]$ and involves sloping potential region up to $0.1 \mathrm{~V}$ and low potential plateau $(<0.1 \mathrm{~V})$. Three different steps are proposed to be involved in $\mathrm{Na}$ insertion into hard carbons, depending on the microstructure, composition and texture of the carbon. Zhang et al. [76] describes them as follows: (i) the uptake of $\mathrm{Na}$ by defects created by heteroatoms such as $\mathrm{O}$ and $\mathrm{N}$, occurring at higher potentials; (ii) the $\mathrm{Na}$ adsorption on disordered isolated graphene sheets resulting in sloping potential between 1 and $0.1 \mathrm{~V}$; and (iii) the mesopore filling occurring at $\sim 0.1 \mathrm{~V}$.

In both lithium and sodium cells, the first charge-discharge cycle records significant irreversible capacity mostly due to the solid electrolyte interphase (SEI) formation but probably also because of some ions being trapped in the bulk of the material [68]. This translates into a lower amount of cyclable sodium and thus lower total battery capacity, which ultimately leads to lower maximum achievable energy density. At first glance, building the cells with the excess of negative active material looks as a promising solution. Unfortunately, sodium deposition upon overcharge or low temperature operation in addition to safety hazards encountered with LIBs proved that this approach should be avoided. Although using ethylene carbonate (EC)-based electrolytes solved the problem for LIBs [69], high irreversible capacity remains a main problem for SIB technology. The correlation between the formation of SEI (and what follows the irreversible capacity) and the surface area of the electrode accessible to the electrolyte is usually related with the BET surface area $[79,82]$. This observation initially recorded for LIBs can be fully transferred to Na cells. Irisarri et al. [68] confirmed it with the series of carbons prepared by pyrolysis of sugar at $1100{ }^{\circ} \mathrm{C}$ under different $\mathrm{Ar}$ flow rates. Carbons characterized by BET surface area of 670,120 and $11 \mathrm{~m}^{2} / \mathrm{g}$ gave $67 \%, 44 \%$ and $32 \%$ of irreversible capacities, respectively, during the first cycle. The same tendency was demonstrated by Simone et al. using cellulose-derived carbons [45].

In addition to BET surface area, the concentration of functional groups on the carbon surface seems to be another relevant parameter affecting the irreversible capacity [77]. While the amount of nitrogen physisorbed on the carbon surface is used to estimate the surface area accessible to the electrolyte, the active surface area (ASA) evaluates the number of active sites on the carbon surface-such as functional groups, adsorbed species and heteroatoms-which can influence the reactivity of the electrolyte [83]. The ASA is obtained by oxygen chemisorption on carbon to form surface-oxygenated complexes which are further quantified by mass spectroscopy during degassing at high temperatures [84]. ASA pertains to the cumulative surface area of different types of defects like vacancies, dislocations, or stacking faults which could be responsible for interactions with the adsorbent. Although the correlation between ASA and irreversible capacity has been demonstrated for LIBs [85], it is still yet to be proved in the case of SIBs.

At present, there are many reports showing hard carbons with very diverse morphologies, microstructures and graphitization degrees and thus different electrochemical performance, as highlighted in Table 1, for biomass waste-derived carbons. The performances of sucrose-derived carbons were presented in detail in a recent review [69] and only mentioned in this work. 
Table 1. Selected literature overview of synthesis conditions of hard carbons, their textural characteristics and their performances as anodes in Na-ion batteries.

\begin{tabular}{|c|c|c|c|c|c|c|c|}
\hline Biomass Precursor & Annealing Conditions & $\operatorname{SSA}\left(\mathrm{m}^{2} \cdot \mathrm{g}^{-1}\right)$ & $\begin{array}{c}\text { Columbic } \\
\text { Efficiency (\%) }\end{array}$ & $\begin{array}{c}\text { Discharge Capacity } \\
\left(\mathrm{mAh} \cdot \mathrm{g}^{-1}\right)\end{array}$ & $\begin{array}{l}\text { Current Density } \\
\left(\mathrm{mA} \cdot \mathrm{g}^{-1}\right)\end{array}$ & $\begin{array}{l}\text { d-Spacing } \\
\text { (Å) }\end{array}$ & Refs. \\
\hline Bleached Softwood Pulp & $1000^{\circ} \mathrm{C} / 2 \mathrm{~h} / \mathrm{Ar}$ & $\begin{array}{c}586 \\
156 \text { (oxidized) }\end{array}$ & 2572 & 252260 & 20 & NA & {$[44]$} \\
\hline Oak Leaves & $1000^{\circ} \mathrm{C} / 1 \mathrm{~h} / \mathrm{Ar}$ & 161 & 75 & 360 & 10 & 3.60 & {$[78]$} \\
\hline Peat Moss & $600-1400^{\circ} \mathrm{C} / 2 \mathrm{~h}$ & $\begin{array}{c}78 \text { to } 54 \\
369 \text { to } 92 \text { (oxidized) }\end{array}$ & $44-64$ & $215-298$ & 50 & $3.82-3.99$ & {$[54]$} \\
\hline Banana Peel & $800-1400^{\circ} \mathrm{C} / 5 \mathrm{~h}$ & $\begin{array}{c}33-14 \\
217-60 \text { (oxidized) }\end{array}$ & $61-73$ & $300-355$ & 50 & $3.86-3.97$ & {$[38]$} \\
\hline Oatmeal & $500-900{ }^{\circ} \mathrm{C} / 2 \mathrm{~h} / \mathrm{N}_{2}$ & $111-23$ & - & $320-164$ & 50 & $3.88-4.18$ & {$[60]$} \\
\hline Shaddock Peel & $800-1400{ }^{\circ} \mathrm{C} / 2 \mathrm{~h} / \mathrm{N}_{2}$ & $26-83$ & - & $263-430$ & 30 & $3.76-3.92$ & {$[41]$} \\
\hline Peanut Skin-Activated $\mathrm{KOH}$ & $800^{\circ} \mathrm{C} / 1 \mathrm{~h} / \mathrm{Ar}$ & $1430-2500$ & $29-34$ & $174-431$ & 100 & $3.70-3.90$ & {$[42]$} \\
\hline Harmful Algal Blooms & $700-900{ }^{\circ} \mathrm{C} / 5 \mathrm{~h} / \mathrm{Ar}$ & - & $46-52$ & $158-231$ & 20 & 3.60 & [49] \\
\hline Pomelo Peel & $700{ }^{\circ} \mathrm{C} / 2 \mathrm{~h} / \mathrm{N}_{2}$ & $\begin{array}{c}0.9 \\
1272\left(\text { activated } \mathrm{H}_{3} \mathrm{PO}_{4}\right)\end{array}$ & 5427 & 215314 & 50 & NA & {$[40]$} \\
\hline Pitch/Lignin & $1200-1600{ }^{\circ} \mathrm{C} / 2 \mathrm{~h} / \mathrm{Ar}$ & 1.3 to 35 & $60-82$ & $205-254$ & 30 & $3.52-3.84$ & {$[47]$} \\
\hline Cellulose & $700-1600^{\circ} \mathrm{C} / 1 \mathrm{~h} / \mathrm{Ar}$ & 1.0 to 380 & $39-84$ & $150-310$ & 37.2 & $3.75-4.20$ & [45] \\
\hline Surcrose & $1100^{\circ} \mathrm{C} / 6 \mathrm{~h} / \mathrm{Ar}$ & $\begin{array}{c}24 \\
135 \text { (ball milled) }\end{array}$ & 6141 & 326210 & $\mathrm{C} / 10$ & 3.873 .43 & {$[82]$} \\
\hline
\end{tabular}


In order to better discriminate between the textural and structural effects on the reversible capacity several literature data are gathered in Figure 7.

Although some systematic studies helped revealing the relationship between the microstructure of hard carbons $\left(\mathrm{d}_{002}\right.$ interlayer spacing, degree of graphitization, micropore size and total pore volume) and reversible capacity, it has been found that sodium insertion between graphene layers is improved with increasing $\mathrm{d}_{002}$ spacing $[32,66]$. Taking a look at Figure $7 \mathrm{a}$, such tendency is not very straightforward. What can be clearly affirmed is that the d-spacing smaller than $3.7 \AA$ is not favorable for obtaining high capacities. A trend for d-spacing greater than $3.8 \AA$ is difficult to be drawn probably due to the different specific surface areas and in some cases also because of the different current density conditions (Table 1). For instance, the shaddock derived hard carbon having a d-spacing of $3.80 \AA$ and a BET surface area of $83 \mathrm{~m}^{2} \cdot \mathrm{g}^{-1}$ exhibits the highest capacity $(431 \mathrm{mAh} / \mathrm{g}$ at $30 \mathrm{~mA} / \mathrm{g})$. For similar d-spacing, cellulose-derived carbon possessing small surface area $\left(\sim 1.0 \mathrm{~m}^{2} \cdot \mathrm{g}^{-1}\right)$ delivers a smaller capacity ( $\sim 290 \mathrm{mAh} / \mathrm{g}$ at $37.2 \mathrm{~mA} / \mathrm{g})$. This may suggest that some porosity is required to achieve better performances. Another reason for these performances maybe the honeycomb-like morphology of the shaddock-derived hard carbon allowing improved Na-ions diffusion in the material.

Concerning the influence of BET surface area on the performances (Figure $7 \mathrm{~b}$ ), smaller surface areas are more favorable for better performances, though this is not always the case. Therefore, for improved capacity, proper structural, textural and morphological carbon characteristics must be combined.
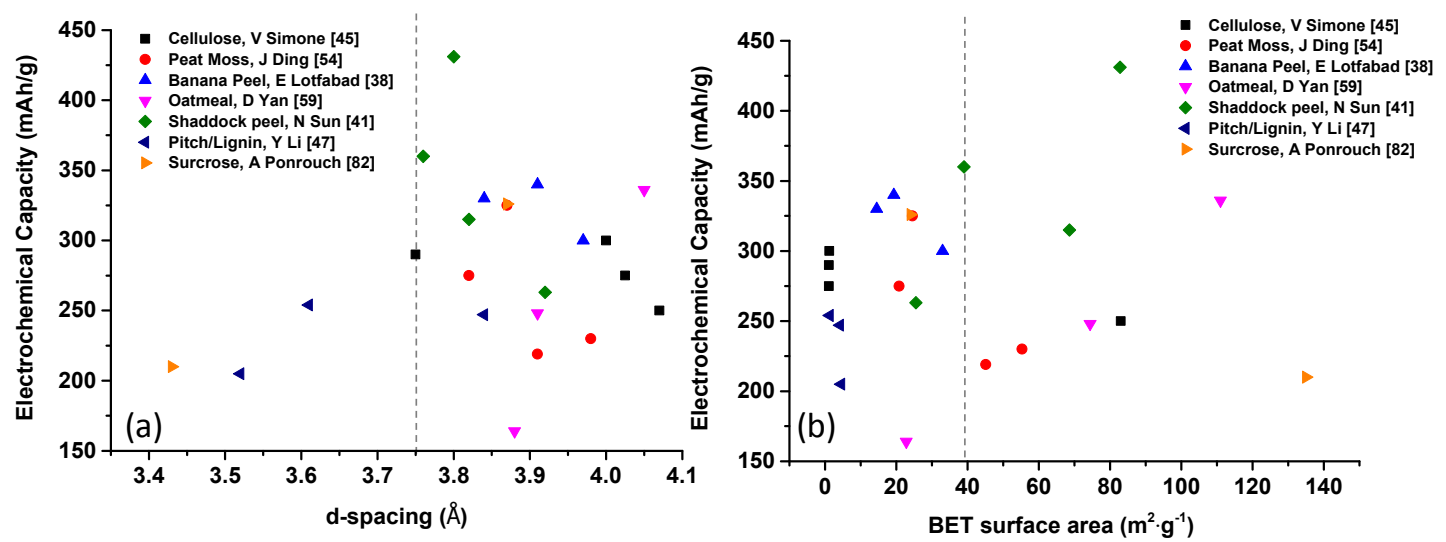

Figure 7. Correlation between the (a) d-spacing and (b) BET surface area and the reversible capacity for several biomass-derived hard carbons.

The use of precursors such as sucrose, glucose or phenolic resins [86-89] resulted in materials with a reversible capacity of 150-300 $\mathrm{mAh} / \mathrm{g}$ but the cyclic performance and rate capability were unsatisfactory to compete with LIBs. Some recent reports strongly suggest that designing a nanostructured morphology $[55,57,89]$ and/or hierarchically porous structure $[90,91]$ or performing heteroatom doping $[92,93]$ is needed to improve the electrochemical performance of carbon materials. Nanostructure can provide active sites for $\mathrm{Na}$-ion storage and decrease the diffusion distance of Na-ions, thus improving the rate capability. One of the earliest works aiming to show a very good rate performance material for sodium ion batteries was prepared by Tang and co-workers [35]. The unique hollow nanosphere structure and carbon shell ordering are behind the superior electrochemical performance of the material obtained by hydrothermal carbonization of glucose in the presence of latex template. Well-connected hollow carbon spheres ensure continuous and efficient electron transport. Moreover, a well-defined and large electrode/electrolyte contact area provides numerous active sites for charge transfer reactions. The very thin shell allows for a short sodium diffusion distance, which is responsible for a very good rate performance. For many materials with layered morphology, some kind of physical activation (dry air at low temperature) $[38,54]$ or chemical activation $(\mathrm{KOH}[42]$, bicarbonate [32], $\mathrm{H}_{3} \mathrm{PO}_{4}$ [40]) was used to create sufficient porosity to reduce the Na diffusion distances, 
thereby improving the rate performance. However, it has to be noted that the chemical activation, except for tuning the porosity, can also produce oxygen-containing functional groups on the carbon surface. These oxygen-bearing groups result in surface redox reactions between these groups and sodium ions, analogous to that of $\mathrm{Li}[94,95]$. Since the amount of activation-created functional groups is closely related to the specific surface area, it is not surprising that high surface area materials exhibit a large amount of oxygen-containing groups as well. This pseudocapacitive effect emerging from the surface redox reactions contribute to the excellent rate performance and high Na capacity as it was demonstrated for $\mathrm{H}_{3} \mathrm{PO}_{4}$-activated carbons. In general, doping with heteroatoms can modify local bonding environment and electron distribution and by this enhance reactivity and electronic conductivity of the electrode material. So far for biowaste-derived carbons, doping with nitrogen, phosphorus and fluorine has been reported utilizing either $\mathrm{H}_{3} \mathrm{PO}_{4},\left(\mathrm{NH}_{4}\right)_{2} \mathrm{HPO}_{4}$ treatments for $\mathrm{N}$ and $\mathrm{P}$ doping $[36,40]$ or taking advantage of the precursor naturally containing heteroatoms in the structure ( $\mathrm{N}$ in oatmeal [59] and $\mathrm{F}$ in lotus petioles [60]). Especially $\mathrm{N}$-doping is known to enhance electrical conductivity by creating edge plane and defect sites, which improves the kinetic performance of the electrode [59].

On the other hand, porosity and high surface area result in very low initial Coulombic efficiency (CE): only $20 \%-50 \%$. In the work of $\mathrm{Li}$ and co-workers [33] monodispersed carbon spherules prepared from sucrose were examined as anode material for SIBs before and after coating with a layer of soft carbon. The results show that the carbon nanoparticles without coating have much higher specific surface area, while the ones coated had very low surface area. This indicates that the layer of soft carbon effectively reduces the exposed surface area. The practical consequence of this was the initial CE improved significantly from $54 \%$ to $85 \%$. Another interesting observation was that in this particular case higher temperature of carbonization led to higher sodium storage capacity, especially the plateau capacity at the low potential region, which is desirable for achieving higher energy density in a full cell. There is also another reason for CE loss, which was explained by Lotfabad et al. [39]. Pseudographitic carbon characterized by excellent Na capacity was prepared by pyrolysis of banana peels but intentionally designed to have low surface area, which disqualified SEI from being a key factor for CE loss. During the first couple of cycles, sodium was irreversibly trapped in the bulk of the material. Gradually increasing graphene interlayer spacing and the intensity of Raman $G$ band suggested that the charge carriers are trapped not only at the graphene defects but also between graphene planes, causing them to order and dilate. After desodiation, the XRD data show that part of the material still exhibits largely dilated interlayer spacing, implying irreversible intercalation of $\mathrm{Na}$ between graphene sheets.

The development of anode materials is very important to promote the commercialization of SIBs. The amorphous carbons are the most promising candidates among all studied anode materials. However, many still do not realize that the cost of carbon materials derived from biomass quickly increases because of low carbon yield. Thus, the challenge is not only to overcome high irreversible capacity loss or low initial CE but also to find the carbon precursor which is cheap and has high carbon content after carbonization. The answer could lie in the approach demonstrated by Li et al. [47], which takes advantage of the emulsification reaction between pitch and lignin. While pitch is known to be one of the cheapest carbon precursors with high carbon yield, lignin suppresses the graphitization of pitch, which would naturally occur during pyrolysis. A sample with the highest reversible capacity of $254 \mathrm{mAh} / \mathrm{g}$-in which the capacity percentage of the plateau region is about $65 \%$-with the highest initial Coulombic efficiency of $82 \%$ and low BET surface area was obtained by mixing pitch and lignin in a $1: 1$ ratio and by carbonizing such a mixture at $1400^{\circ} \mathrm{C}$. This seems to be a very effective strategy to employ pitch in the preparation of amorphous carbons with excellent electrochemical performance, which can be extended to other electrode materials in the future. 


\section{Conclusions}

Hard carbons derived from biomass hold great promise in fulfilling the requirements of good performance and sustainability placed upon materials used for sodium ion batteries (SIBs) to make them a viable alternative to lithium ion batteries (LIBs). In order to do so, more systematic studies are needed to gain better understanding of the relationship between proper carbon precursor, synthesis/pyrolysis parameters, their microstructure and the final performance. Thanks to a growing number of reports in this area, more insight into the mechanism of $\mathrm{Na}$ intercalation into carbon materials is gained, thus bringing even closer solutions for existing performance bottlenecks. As summarized in this work, large $\mathrm{d}_{002}$ spacing, low graphitization degree, in addition to tailored porosity affect the $\mathrm{Na}$ adsorption ability and should be carefully tuned by choice of proper pre- or post-pyrolysis treatments to obtain optimum performance, which is at the foundation of application prospects.

Acknowledgments: The authors acknowledge financial support of this work through the European Union's Horizon 2020 Programme (project NAIADES, call: LCE10-2014, Contract no. 646433) and the RS2E network.

Conflicts of Interest: The authors declare no conflict of interest.

\section{References}

1. Greenwood, N.N.; Earnshaw, A. Chemistry of the Elements, 2nd ed.; Butterworth-Heinemann: Oxford, UK, 1997.

2. Lide, D.R. CRC Handbook of Chemistry and Physics, 88th ed.; Taylor \& Francis Group: Boca Raton, FL, USA, 2008.

3. Ellis, B.L.; Nazar, L.F. Sodium and sodium-ion energy storage batteries. Curr. Opin. Solid State Mater. Sci. 2012, 16, 168-177. [CrossRef]

4. Goodenough, J.B. Rechargeable batteries: Challenges old and new. J. Solid State Electrochem. 2012, 16, 2019-2029. [CrossRef]

5. Sun, Q.; Yang, Y.; Fu, Z.W. Electrochemical properties of room temperature sodium-air batteries with non-aqueous electrolyte. Electrochem. Commun. 2012, 16, 22-25. [CrossRef]

6. Kummer, J.T.; Weber, N. Battery Having a Molten Alkali Metal Anode and Molten Sulfur Cathode. U.S. Patent 3,413,150, 26 November 1968.

7. Sudworth, J.L. The sodium/nickel chloride (ZEBRA) battery. J. Power Sources 2001, 100, 149-163. [CrossRef]

8. Bullis, K. Sodium-Ion Cells for Cheap Energy Storage; MIT Technology Review: Cambridge, MA, USA, 2009.

9. Pan, H.; Hu, Y.S.; Chen, L. Room-temperature stationary sodium-ion batteries for large-scale electric energy storage. Energy Environ. Sci. 2013, 6, 2338-2360. [CrossRef]

10. Liu, Y.; Merinov, B.V.; Goddard, W.A. Origin of low sodium capacity in graphite and generally weak substrate binding of $\mathrm{Na}$ and $\mathrm{Mg}$ among alkali and alkaline earth metals. Proc. Natl. Acad. Sci. USA 2016, 113, 3735-3739. [CrossRef] [PubMed]

11. Nita, C.; Bensafia, M.; Vaulot, C.; Delmotte, L.; Matei Ghimbeu, C. Insights on the synthesis mechanism of green phenolic resin derived porous carbons via a salt-soft templating approach. Carbon 2016, 109, $227-238$. [CrossRef]

12. Kumpf, R.; Dougherty, D. A mechanism for ion selectivity in potasium channels: Computational studies of cation-pi interactions. Science 1993, 261, 1708-1710. [CrossRef] [PubMed]

13. Shannon, R.D. Revised effective ionic radii and systematic studies of interatomic distances in halides and chalcogenides. Acta Crystallogr. 1976, A32, 751-767. [CrossRef]

14. Slater, M.D.; Kim, D.; Lee, E.; Johnson, C.S. Sodium ion batteries. Grand challenges in energy storage. Adv. Funct. Mater. 2013, 23, 917-1089. [CrossRef]

15. Asher, R.C. A lamellar compound of sodium and graphite. J. Inorg. Nucl. Chem. 1959, 10, 238-249. [CrossRef]

16. Ge, P.; Fouletier, M. Electrochemical intercalation of sodium in graphite. Solid State Ion. 1988, 30, 1172-1175. [CrossRef]

17. Stevens, D.A.; Dahn, J.R. The mechanisms of lithium and sodium insertion in carbon materials. J. Electrochem. Soc. 2001, 148, A803-A811. [CrossRef] 
18. Ponrouch, A.; Dedryvère, R.; Monti, D.; Demet, A.E.; Ateba Mba, J.M.; Croguennec, L.; Masquelier, C.; Johansson, P.; Palacín, M.R. Towards high energy density sodium ion batteries through electrolyte optimization. Energy Environ. Sci. 2013, 6, 2361-2369. [CrossRef]

19. Franklin, R.E. Crystallite growth in graphitizing and non-graphitizing carbons. Proc. R. Soc. Lond. Ser. A 1951, 209, 196-218. [CrossRef]

20. Al-Muhtaseb, S.A.; Ritter, J.A. Preparation and properties of resorcinol-formaldehyde organic and carbon gels. Adv. Mater. 2003, 15, 101-114. [CrossRef]

21. Liang, C.; Li, Z.; Dai, S. Mesoporous carbon materials: Synthesis and modification. Angew. Chem. Int. Ed. 2008, 47, 3696-3717. [CrossRef] [PubMed]

22. Wan, Y.; Shi, Y.; Zhao, D. Supramolecular aggregates as templates: Ordered mesoporous polymers and carbons. Chem. Mater. 2008, 20, 932-945. [CrossRef]

23. Ma, T.-Y.; Liu, L.; Yuan, Z.-Y. Direct synthesis of ordered mesoporous carbons. Chem. Soc. Rev. 2013, 42, 3977-4003. [CrossRef] [PubMed]

24. Yan, Y.; Yin, Y.-X.; Guo, Y.-G.; Wan, L.Y. A Sandwich-Like Hierarchically Porous Carbon/Graphene Composite as a High-Performance Anode Material for Sodium-Ion Batteries. Adv. Energy Mater. 2014, 4, 1301584. [CrossRef]

25. Wen, Y.; He, K.; Zhu, Y.; Han, F.; Xu, Y.; Matsuda, I.; Ishii, Y.; Cumings, J.; Wang, C. Expanded graphite as superior anode for sodium-ion batteries. Nat. Commun. 2014, 5, 4033-4043. [CrossRef] [PubMed]

26. Hou, H.; Banks, C.E.; Jing, M.; Zhang, Y.; Ji, X. Carbon Quantum Dots and Their Derivative 3D Porous Carbon Frameworks for Sodium-Ion Batteries with Ultralong Cycle Life. Adv. Mater. 2015, 27, 7861-7866. [CrossRef] [PubMed]

27. Hou, H.; Shao, L.; Zhang, Y.; Zou, G.; Chen, J.; Ji, X. Large-Area Carbon Nanosheets Doped with Phosphorus: A High-Performance Anode Material for Sodium-Ion Batteries. Adv. Sci. 2016, 1600243-1600254. [CrossRef]

28. Peled, E.; Eshkenazi, V.; Rosenberg, Y. Study of lithium insertion in hard carbon made from cotton wool. J. Power Sources 1998, 76, 153-158. [CrossRef]

29. Xu, H.; Zhang, H.; Ouyang, Y.; Liu, L.; Wang, Y. Two-dimensional hierarchical porous carbon composites derived from corn stalks for electrode materials with high performance. Electrochim. Acta 2016, 214, 119-128. [CrossRef]

30. Jiang, Q.; Zhang, Z.; Yin, S.; Guo, Z.; Wang, S.; Feng, C. Biomass carbon micro/nano-structures derived from ramie fibers and corncobs as anode materials for lithium-ion and sodium-ion batteries. Appl. Surf. Sci. 2016, 379, 73-82. [CrossRef]

31. Yang, T.; Qian, T.; Wang, M.; Shen, X.; Xu, N.; Sun, Z.; Yan, C. A Sustainable Route from Biomass Byproduct Okara to High Content Nitrogen-Doped Carbon Sheets for Efficient Sodium Ion Batteries. Adv. Mater. 2016, 28, 539-545. [CrossRef] [PubMed]

32. Prabakar, S.J.R.; Jeong, J.; Pyo, M. Nanoporous hard carbon anodes for improved electrochemical performance in sodium ion batteries. Electrochim. Acta 2015, 161, 23-31. [CrossRef]

33. Li, Y.; Xu, S.; Wu, X.; Yu, J.; Wang, Y.; Hu, Y.-S.; Li, H.; Chen, L.; Huang, X. Amorphous monodispersed hard carbon microspherules derived from biomass as a high performance negative electrode material for sodium-ion batteries. J. Mater. Chem. A 2015, 3, 71-77. [CrossRef]

34. Bommier, C.; Luo, W.; Gao, W.-Y.; Greaney, A.; Ma, S.; Ji, X. Predicting capacity of hard carbon anodes in sodium-ion batteries using porosity measurements. Carbon 2014, 76, 165-174. [CrossRef]

35. Tang, K.; Fu, L.; White, R.J.; Yu, L.; Titirici, M.-M.; Antonietti, M.; Maier, J. Hollow Carbon Nanospheres with Superior Rate Capability for Sodium-Based Batteries. Adv. Energy Mater. 2012, 2, 873-877. [CrossRef]

36. Li, Y.; Wang, Z.; Li, L.; Peng, S.; Zhang, L.; Srinivasan, M.; Ramakrishna, S. Preparation of nitrogen- and phosphorous co-doped carbon microspheres and their superior performance as anode in sodium-ion batteries. Carbon 2016, 99, 556-563. [CrossRef]

37. Wu, L.; Buchholz, D.; Vaalma, C.; Giffin, G.A.; Passerini, S. Apple-Biowaste-Derived Hard Carbon as a Powerful Anode Material for Na-Ion Batteries. ChemElectroChem 2016, 3, 292-298. [CrossRef]

38. Lotfabad, E.M.; Ding, J.; Cui, K.; Kohandehghan, A.; Kalisvaart, W.P.; Hazelton, M.; Mitlin, D. High-Density Sodium and Lithium Ion Battery Anodes from Banana Peels. ACS Nano 2014, 8, 7115-7129. [CrossRef] [PubMed] 
39. Lotfabad, E.M.; Kalisvaart, P.; Kohandehghan, A.; Karpuzovc, D.; Mitlin, D. Origin of non-SEI related coulombic efficiency loss in carbons tested against Na and Li. J. Mater. Chem. A 2014, 2, 19685-19695. [CrossRef]

40. Hong, K.-L.; Qie, L.; Zeng, R.; Yi, Z.-Q.; Zhang, W.; Wang, D.; Yin, W.; Wu, C.; Fan, Q.-J.; Zhang, W.-X.; et al. Biomass derived hard carbon used as a high performance anode material for sodium ion batteries. J. Mater. Chem. A 2014, 2, 12733-12738. [CrossRef]

41. Sun, N.; Liu, H.; Xu, B. Facile synthesis of high performance hard carbon anode materials for sodium ion batteries. J. Mater. Chem. A 2015, 3, 20560-20566. [CrossRef]

42. Wang, H.; Yu, W.; Shi, J.; Mao, N.; Chen, S.; Liu, W. Biomass derived hierarchical porous carbons as high-performance anodes for sodium-ion batteries. Electrochim. Acta 2016, 188, 103-110. [CrossRef]

43. Luo, W.; Schardt, J.; Bommier, C.; Wang, B.; Razink, J.; Simonsen, J.; Ji, X. Carbon nanofibers derived from cellulose nanofibers as a long-life anode material for rechargeable sodium-ion batteries. J. Mater. Chem. A 2013, 1, 10662-10666. [CrossRef]

44. Shen, F.; Zhu, H.; Luo, W.; Wan, J.; Zhou, L.; Dai, J.; Zhao, B.; Han, X.; Fu, K.; Hu, L. Chemically Crushed Wood Cellulose Fiber towards High- Performance Sodium-Ion Batteries. ACS Appl. Mater. Interfaces 2015, 7, 23291-23296. [CrossRef] [PubMed]

45. Simone, V.; Boulineau, A.; de Geyer, A.; Rouchon, D.; Simonin, L.; Martinet, S. Hard carbon derived from cellulose as anode for sodium ion batteries: Dependence of electrochemical properties on structure. J. Energy Chem. 2016, 25, 761-768. [CrossRef]

46. Jin, J.; Yu, B.-J.; Shi, Z.-Q.; Wang, C.-Y.; Chong, C.-B. Lignin-based electrospun carbon nanofibrous webs as free-standing and binder-free electrodes for sodium ion batteries. J. Power Source 2014, 272, 800-807. [CrossRef]

47. Li, Y.; Hu, Y.-S.; Li, H.; Chen, L.; Huang, X. A superior low-cost amorphous carbon anode made from pitch and lignin for sodium-ion batteries. J. Mater. Chem. A 2016, 4, 96-104. [CrossRef]

48. Yun, Y.S.; Park, K.-Y.; Lee, B.; Cho, S.Y.; Park, Y.-U.; Hong, S.J.; Kim, B.H.; Gwon, H.; Kim, H.; Lee, S.; et al. Sodium-Ion Storage in Pyroprotein-Based Carbon Nanoplates. Adv. Mater. 2015, 27, 6914-6921. [CrossRef] [PubMed]

49. Meng, X.; Savage, P.E.; Deng, D. Trash to Treasure: From Harmful Algal Blooms to High-Performance Electrodes for Sodium-Ion Batteries. Environ. Sci. Technol. 2015, 49, 12543-12550. [CrossRef] [PubMed]

50. Emaga, T.H.; Robert, C.; Ronkart, S.N.; Wathelet, B.; Paquot, M. Dietary Fibre Components and Pectin Chemical Features of Peels during Ripening in Banana and Plantain Varieties. Bioresour. Technol. 2008, 99, 4346-4354. [CrossRef] [PubMed]

51. Titirici, M.M.; Thomas, A.; Yu, S.-H.; Müller, J.-O.; Antonietti, M. A Direct Synthesis of Mesoporous Carbons with Bicontinuous Pore Morphology from Crude Plant Material by Hydrothermal Carbonization. Chem. Mater. 2007, 19, 4205-4212. [CrossRef]

52. Dahn, J.R.; Zheng, T.; Liu, Y.; Xue, J.S. Mechanisms for Lithium Insertion in Carbonaceous Materials. Science 1995, 270, 590-593. [CrossRef]

53. Wandee, Y.; Uttapap, D.; Puncha-arnon, S.; Puttanlek, C.; Rungsardthong, V.; Wetprasit, N. Enrichment of rice noodles with fibre-rich fractions derived from cassava pulp and pomelo peel. Int. J. Food Sci. Technol. 2014, 49, 2348-2355. [CrossRef]

54. Ding, J.; Wang, H.; Li, Z.; Kohandehghan, A.; Cui, K.; Xu, Z.; Zahiri, B.; Tan, X.; Lotfabad, E.M.; Olsen, B.C.; et al. Carbon Nanosheet Frameworks Derived from Peat Moss as High Performance Sodium Ion Battery Anodes. ACS Nano 2013, 7, 11004-11015. [CrossRef] [PubMed]

55. Fu, L.J.; Tang, K.; Song, K.P.; Aken, P.A.V.; Yu, Y.; Maier, J. Nitrogen doped porous carbon fibres as anode materials for sodium ion batteries with excellent rate performance. Nanoscale 2014, 6, 1384-1389. [CrossRef] [PubMed]

56. Wang, Z.H.; Qie, L.; Yuan, L.X.; Zhang, W.X.; Hu, X.L.; Huang, Y.H. Functionalized N-doped interconnected carbon nanofibers as an anode material for sodium-ion storage with excellent performance. Carbon 2013, 55, 328-334. [CrossRef]

57. Wang, H.G.; Wu, Z.; Meng, F.L.; Ma, D.L.; Huang, X.L.; Wang, L.M.; Zhang, X.B. Nitrogen-doped porous carbon nanosheets as low-cost, high-performance anode material for sodium-ion batteries. ChemSusChem 2013, 6, 56-60. [CrossRef] [PubMed] 
58. Xu, J.T.; Wang, M.; Wickramaratne, N.P.; Jaroniec, M.; Dou, S.Q.; Dai, L.M. High-performance sodium ion batteries based on a 3D anode from nitrogen-doped graphene foams. Adv. Mater. 2015, 27, 2042-2048. [CrossRef] [PubMed]

59. Yan, D.; Yu, C.; Zhang, X.; Qin, W.; Lu, T.; Hu, B.; Li, H.; Pan, L. Nitrogen-doped carbon microspheres derived from oatmeal as high capacity and superior long life anode material for sodium ion battery. Electrochim. Acta 2016, 191, 385-391. [CrossRef]

60. Wang, P.; Qiao, B.; Du, Y.; Li, Y.; Zhou, X.; Dai, Z.; Bao, J. Fluorine-Doped Carbon Particles Derived from Lotus Petioles as High-Performance Anode Materials for Sodium-Ion Batteries. J. Phys. Chem. C 2015, 119, 21336-21344. [CrossRef]

61. Demirbas, A. Combustion characteristics of different biomass fuels. Prog. Energy Combust. Sci. 2004, 30, 219-230. [CrossRef]

62. Bouraoui, Z.; Jeguirim, M.; Guizani, C.; Limousy, L.; Dupont, C.; Gadiou, R. Thermogravimetric study on the influence of structural, textural andchemical properties of biomass chars on $\mathrm{CO}_{2}$ gasification reactivity. Energy 2015, 88, 703-710. [CrossRef]

63. Kraiem, N.; Lajili, M.; Limousy, L.; Said, R.; Jeguirim, M. Energy recovery from Tunisian agri-food wastes: Evaluation of combustion performance and emissions characteristics of green pellets prepared from tomato residues and grape marc. Energy 2016, 107, 409-418. [CrossRef]

64. Dahn, J.R.; Sleigh, A.K.; Shi, H.; Reimers, J.N.; Zhong, Q.; Way, B.M. Dependence of the electrochemical intercalation of lithium in carbons on the crystal-structure of the carbon. Electrochim. Acta 1993, 38, 1179-1191. [CrossRef]

65. Liu, Y.; Xue, J.S.; Zheng, T.; Dahn, J.R. Mechanism of lithium insertion in hard carbons prepared by pyrolysis of epoxy resins. Carbon 1996, 34, 193-200. [CrossRef]

66. Jin, J.; Shi, Z.-Q.; Wang, C.-Y. Electrochemical Performance of Electrospun carbon nanofibers as free-standing and binder-free anodes for Sodium-Ion and Lithium-Ion Batteries. Electrochim. Acta 2014, 141, 302-310. [CrossRef]

67. Dahn, J.R.; Xing, W.; Gao, Y. The "falling cards model" for the structure of microporous carbons. Carbon 1997, 35, 825-830. [CrossRef]

68. Irisarri, E.; Ponrouch, A.; Palacin, M.R. Review-Hard Carbon Negative Electrode Materials for Sodium-Ion Batteries. J. Electrochem. Soc. 2015, 162, A2476-A2482. [CrossRef]

69. Winter, M.; Besenhard, J.O. Handbook of Battery Materials, 2nd ed.; Daniel, C., Besenhard, J.O., Eds.; Wiley: Hoboken, NJ, USA, 2011.

70. Gibaud, A.; Xue, J.S.; Dahn, J.R. A small angle X-ray scattering study of carbons made from pyrolyzed sugar. Carbon 1996, 34, 499-503. [CrossRef]

71. Xing, W.; Xue, J.S.; Dahn, J.R. Optimizing pyrolysis of sugar carbons for use as anode materials in lithium-ion batteries. J. Electrochem. Soc. 1996, 143, 3046-3052. [CrossRef]

72. Buiel, E.R.; George, A.E.; Dahn, J.R. Model of micropore closure in hard carbon prepared from sucrose. Carbon 1999, 37, 1399-1407. [CrossRef]

73. Luo, W.; Bommier, C.; Jian, Z.; Li, X.; Carter, R.; Vail, S.; Lu, Y.; Lee, J.-J.; Ji, X. Low-Surface-Area Hard Carbon Anode for Na-Ion Batteries via Graphene Oxide as a Dehydration Agent. ACS Appl. Mater. Interfaces 2015, 7, 2626-2631. [CrossRef] [PubMed]

74. Gaddam, R.R.; Yang, D.; Narayan, R.; Raju, K.V.S.N.; Kumar, N.A.; Zhao, X.S. Biomass derived carbon nanoparticle as anodes for high performance sodium and lithium ion batteries. Nano Energy 2016, 26, $346-352$. [CrossRef]

75. Zhang, B.; Kang, F.; Tarascon, J.-M.; Kim, J.-K. Recent advances in electrospun carbon nanofibers and their application in electrochemical energy storage. Prog. Mater. Sci. 2016, 76, 319-380. [CrossRef]

76. Zhang, B.; Matei Ghimbeu, C.; Laberty, C.; Vix-Guterl, C.; Tarascon, J.-M. Correlation between Microstructure and Na Storage Behavior in Hard Carbon. Adv. Energy Mater. 2016, 6, 1501588. [CrossRef]

77. Bold, H.C. Morphology of Plants; Joanna Cotler Books: New York, NY, USA, 1967; pp. 225-229.

78. Li, H.; Shen, F.; Luo, W.; Dai, J.; Han, X.; Chen, Y.; Yao, J.; Zhu, H.; Fu, K.; Hitz, E.; et al. Carbonized-leaf Membrane with Anisotropic Surfaces for Sodium-ion Battery. ACS Appl. Mater. Interfaces 2016, 8, 2204-2210. [CrossRef] [PubMed]

79. Berger, D.; Carton, B.; Herold, A.; Metrot, A. Insertion of sodium and potassium in some hard carbons. C. R. Acad. Sci. Paris Ser. C 1970, 271, 837-840. 
80. Alcantara, R.; Ortiz, G.F.; Lavela, P.; Tirado, J.L. EPR, NMR, and electrochemical studies of surface-modified carbon microbeads. Chem. Mater. 2006, 18, 2293-2301. [CrossRef]

81. Gotoh, K.; Ishikawa, T.; Shimadzu, S.; Yabuuchi, N.; Komaba, S.; Takeda, K.; Goto, A.; Deguchi, K.; Ohki, S.; Hashi, K.; et al. NMR study for electrochemically inserted Na in hard carbon electrode of sodium ion battery. J. Power Sources 2013, 225, 137-140. [CrossRef]

82. Ponrouch, A.; Goni, A.R.; Palacin, M.R. High capacity hard carbon anodes for sodium ion batteries in additive free electrolyte. Electrochem. Commun. 2013, 27, 85-88. [CrossRef]

83. Larcher, D.; Mudalige, C.; Gharghouri, M.; Dahn, J.R. Electrochemical insertion of Li and irreversibility in disordered carbons prepared from oxygen and sulfur-containing pitches. Electrochim. Acta 1999, 44, 4069-4072. [CrossRef]

84. Beguin, F.; Chevallier, F.; Vix-Guterl, C.; Saadallah, S.; Bertagna, V.; Rouzaud, J.N.; Frackowiak, E. Correlation of the irreversible lithium capacity with the active surface area of modified carbons. Carbon 2005, 43, 2160-2167. [CrossRef]

85. Beguin, F.; Chevallier, F.; Vix-Guterl, C.; Saadallah, S.; Bertagna, V.; Rouzaud, J.N.; Frackowiak, E. New Carbon Based Materials for Electrochemical Energy Storage Systems; Barsukov, E., Ed.; Springer: Dordrecht, The Netherlands, 2006; p. 231.

86. Chen, T.; Pan, L.; Lu, T.; Fu, C.; Chua, D.H.C.; Sun, Z. Fast synthesis of carbon microspheres via a microwave-assisted reaction for sodium ion batteries. J. Mater. Chem. A 2014, 2, 1263-1267. [CrossRef]

87. Stevens, D.A.; Dahn, J.R. High capacity anode materials for rechargeable sodium-ion batteries. J. Electrochem. Soc. 2000, 147, 1271-1273. [CrossRef]

88. Liu, J.; Liu, H.; Yang, T.; Wang, G.; Tade, M.O. Mesoporous carbon with large pores as anode for Na-ion batteries. Chin. Sci. Bull. 2014, 59, 2186-2190. [CrossRef]

89. Cao, Y.; Xiao, L.; Sushko, M.L.; Wang, W.; Schwenzer, B.; Xiao, J.; Nie, Z.; Saraf, L.V.; Yang, Z.; Liu, J. Sodium Ion Insertion in Hollow Carbon Nanowires for Battery Applications. Nano Lett. 2012, 12, 3783-3787. [CrossRef] [PubMed]

90. Wenzel, S.; Hara, T.; Janek, J.; Adelhelm, P. Room-temperature sodium-ion batteries: Improving the rate capability of carbon anode materials by templating strategies. Energy Environ. Sci. 2011, 4, 3342-3345. [CrossRef]

91. Song, H.; Li, N.; Cui, H.; Wang, C. Enhanced storage capability and kinetic processes by pores- and hetero-atoms-riched carbon nanobubbles for lithium-ion and sodium-ion batteries anodes. Nano Energy 2014, 4, 81-87. [CrossRef]

92. Tong, Y.C.; Zhang, X.Y.; Wang, Q.Y.; Xu, X.J. The adsorption mechanism of platinum on phosphorus-doped single walled carbon nanotube. Comput. Theor. Chem. 2015, 1059, 1-6. [CrossRef]

93. Puziy, A.M.; Poddubnaya, O.I.; Alonso, A.M.; Garcia, F.S.; Tascon, J.M.D. Synthetic carbons activated with phosphoric acid: II. Porous structure. Carbon 2002, 40, 1507-1519. [CrossRef]

94. Shao, Y.-Y.; Xiao, J.; Wang, W.; Engelhard, M.; Chen, X.L.; Nie, Z.M.; Gu, M.; Saraf, L.V.; Exarhos, G.; Zhang, J.G.; et al. Surface-Driven Sodium Ion Energy Storage in Nanocellular Carbon Foams. Nano Lett. 2013, 13, 3909-3914. [CrossRef] [PubMed]

95. Byon, H.R.; Gallant, B.M.; Lee, S.W.; Horn, Y.S. Role of Oxygen Functional Groups in Carbon Nanotube/Graphene Freestanding Electrodes for High Performance Lithium Batteries. Adv. Funct. Mater. 2013, 23, 1037-1045. [CrossRef]

(C) 2016 by the authors; licensee MDPI, Basel, Switzerland. This article is an open access article distributed under the terms and conditions of the Creative Commons Attribution (CC-BY) license (http:/ / creativecommons.org/licenses/by/4.0/). 